\title{
CARACTERIZAÇÃO FÍSICA DE CINZAS PESADAS E LEVES PROVENIENTES DA GASEIFICAÇÃO DO CARVÃO MINERAL DE CANDIOTA/RS VISANDO APLICAÇÃO INDUSTRIAL
}

\author{
P. B. RIBEIRO ${ }^{1}$, I. N. RAUPP ${ }^{1}$, F. D. SÁ ${ }^{1}$ e A. R. C. MUNIZ ${ }^{1}$ \\ ${ }^{1}$ Universidade Federal do Pampa, Laboratório de Energia e Carboquímica \\ E-mail para contato: pri.baruffi@gmail.com
}

\begin{abstract}
RESUMO - As jazidas de Candiota detém 42,9\% das reservas de carvão brasileiro. Esse carvão, que possui alto teor de cinzas, é utilizado para a produção de energia por meio de combustão. Porém, esse apresenta baixa eficiência de processo, além de questões ambientais, que colocam uma série de desafios técnicos e econômicos para uso mais limpo do carvão. A gaseificação surge como uma opção atraente, uma vez que permite maior eficiência de conversão energética e, ambientalmente, é sustentável. Em particular, oferece alta eficiência em carvões de alto teor de cinzas e umidade, as emissões são reduzidas e o potencial para reutilização dos coprodutos é grande, sendo considerada uma tecnologia limpa. O presente trabalho teve como objetivo principal caracterizar as cinzas provenientes da gaseificação em leito fluidizado, em escala piloto, visando avaliar perspectivas de aproveitamento. Concluiu-se com análises que as cinzas pesadas e leves possuem características físicas com potencial para serem aproveitadas como matéria-prima para desenvolvimento de outros produtos.
\end{abstract}

\section{INTRODUÇÃO}

O termo gaseificação tem por definição, a reação de um combustível sólido com o vapor d'água ou dióxido de carbono submetido à alta temperatura, obtendo-se um produto gasoso denominado gás de síntese ou syngas. Este, destina-se à geração de energia ou serve como matéria-prima para outro processo (Nunes, 2012). É uma alternativa para estudar a redução dos impactos ambientais e aumentar o rendimento de carvão distinguindo-se de outras rotas, pelo desenvolvimento e uso de tecnologias que visam mitigar os níveis de emissão sem comprometer sua eficiência térmica (Pellegrino, 2006). A rota de gaseificação é vantajosa quanto à permanência das cinzas residuais no gaseificador, ocasionando a diminuição das emissões atmosféricas e obtendo-se um combustível produzido mais limpo. Da mesma forma, associada a catalisadores, aumenta a produção de hidrogênio e monóxido de carbono e diminui a produção de dióxido de carbono (Nascimento, 2014). O gaseificador abordado neste trabalho é do tipo leito fluidizado borbulhante. Esse gaseificador é o mais indicado para carvões de altos teores de cinzas, visto que a cinza em suspensão cria melhores condições de transferência de calor no interior do gaseificador e a água é imprescindível no processo de gaseificação (Melo, 2013).

O presente trabalho teve como objetivo principal investigar as cinzas pesadas e leves provindas do processo de gaseificação em leito fluidizado, em escala piloto, visando avaliar perspectivas de aproveitamento. A caracterização tem por finalidade conhecimento a cerca de 
parâmetros físicos, que, através dos quais objetiva-se identificar alternativas de aplicação para melhor uso deste coproduto e contribuição para a sustentabilidade ambiental e econômica da região.

\section{MATERIAS E MÉTODOS}

Para conhecimento das características físicas das cinzas leves e pesadas, realizou-se análises de granulometria, colorimetria, área superficial, volume de poro e raio médio de poro, conforme equipamentos expostos na Figura 1.

Figura 1 - Fluxograma representativo com equipamentos usados para caracterização das cinzas leves e pesadas

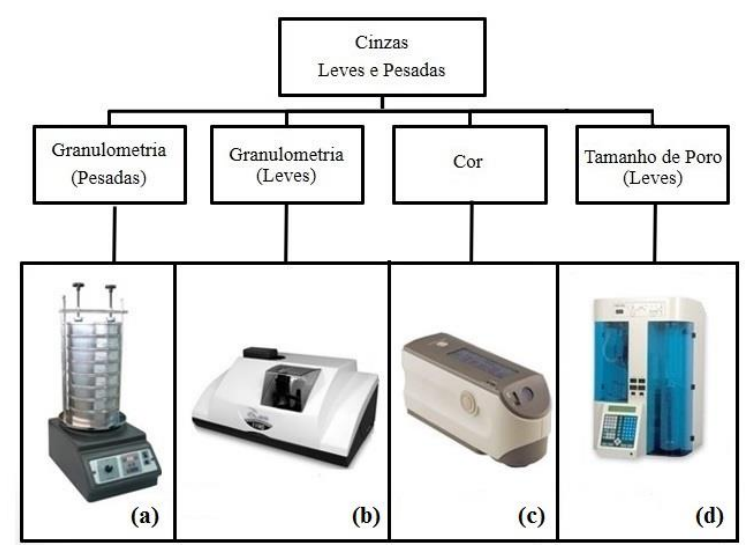

*(a) Conjunto de peneiras e agitador mecânico; (b) Granulômetro; (c) Picnômetro Gasoso; (d) Porosímetro.

Realizaram-se diferentes análises de granulometria para cada tipo de cinza, devido suas características serem visualmente diferentes. As cinzas pesadas foram caracterizadas pela distribuição granulométrica, utilizando-se um conjunto de peneiras fabricadas nos padrões ABNT/ASTM/TYLER, conforme Figura 1, item (a). A análise granulométrica para as cinzas leves foi feita em equipamento de análise por espalhamento de laser, modelo Granulometer 1190, marca Cilas, a faixa de medida foi de 0,04 a $500 \mu \mathrm{m}$, equipamento presente na Figura 1 no item (b). A colorimetria das cinzas foi realizada com cinco leituras de amostras. $\mathrm{O}$ Espectrofotômetro/Colorímetro usado é da marca Konica Minolta, modelo CM-2500d, conforme representado no item (c) presente na Figura 1 e, usando padrão CIELAB. A fração de poros vazios presentes nas cinzas foi medida através de área superficial, utilizado equipamento da marca Quantachrome Instruments, modelo NOVA 4200e, que funciona com adição de quantidades conhecidas de pressão de nitrogênio ao recipiente da amostra, sendo esta, monitorada por um sensor. Na Figura 1, o item (d). Nesse trabalho, a partir dos resultados obtidos pela caracterização das cinzas foi possível realizar um estudo de viabilidade de aplicação destas em processos industriais, objetivando agregar valor a este resíduo mineral.

\section{RESULTADOS E DISCUSSÃO}

\subsection{Granulometria}


As cinzas geradas no processo dispostas na Figura 2, item (a) são as cinzas pesadas e o item (b) representa as cinzas leves originárias do processo de gaseificação.

Figura 2 - (a) Cinzas pesadas e (b) Cinzas leves.
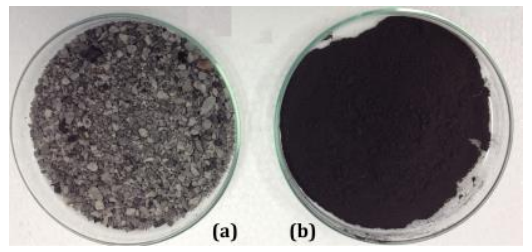

Para a análise granulométrica das cinzas leves o diâmetro médio da partícula foi de $23,41 \mu \mathrm{m}$. A Figura 3, representa a análise granulométrica diferencial realizada para as cinzas leves de carvão mineral. Observa-se que o diâmetro médio foi de $23,41 \mu \mathrm{m}$ no ponto de intersecção entre a a curva da fração retida acumulada e a curva granulométrica diferencial, também, o máximo da curva ocorre no ponto a aproximadamente $40 \mu \mathrm{m}$, sendo esta a maior granulometria que pode ser observada para as cinzas leves.

Figura 3 - Análise Granulométrica Diferencial para cinzas leves.

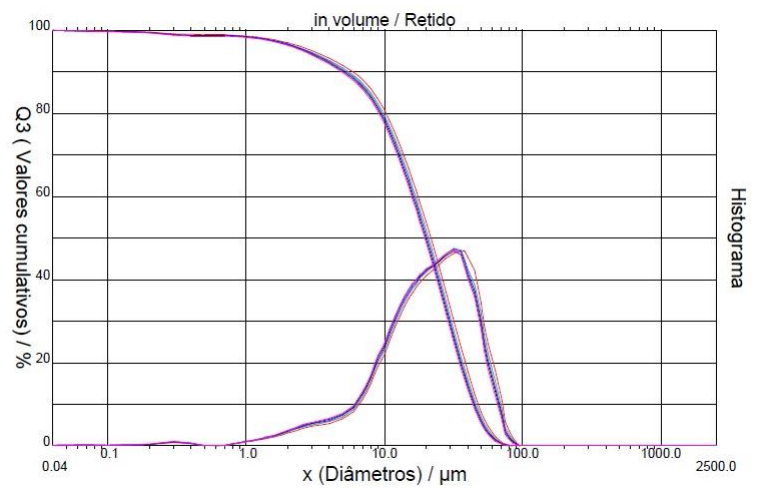

Pires e Querol (2004) analisaram cinzas leves da Usina Termelétrica de Candiota obtendo diâmetro médio de 49,30 $\mu \mathrm{m}$. A discrepância nos diâmetros encontrados pode ser explicada pela presença de material carbonáceo não queimado durante a combustão, fato que difere da gaseificação, pois o carvão possui granulometria inferior quando inserido no leito para inicio das reações de gaseificação. $\mathrm{O}$ diâmetro médio das cinzas pesadas foi de 0,504 mm. O diâmetro médio de Sauter obtido que, de acordo com Cremasco (2012), é a relação superfície/volume igualitária para todas as partículas, para esta análise foi dee 1,983 $\mathrm{mm}$. A Figura 4 ilustra as frações retidas em cada peneira. $\mathrm{O}$ item (a) da figura refere-se às frações retidas nas peneiras de tyler 6, 9 e 32; o item (b) à peneira de tyler 60, onde 73,38\% da massa de cinzas adicionada nas peneiras ficou retida. Essa massa refere-se, em parte, à areia de quartzo, que é coletada no primeiro tambor juntamente com as cinzas pesadas. A areia presente neste tambor é o agente fluidizante do processo de gaseificação, o combustível é mantido suspenso em um leito de areia para favorecer as condições de transferência de calor e homogeneizar a temperatura no reator. $\mathrm{O}$ item (c) equivale ao char, ou seja, carvão pirolisado, como fração passante das peneiras de tyler 115 e 270 e retida no fundo. Isso pode ser observado através da análise de distribuição granulométrica diferencial. 


\section{Congresso Brasileiro de Engenharia Química em Iniciação Científica UFSCar - São Carlos - SP 16 a 19 de Julho de 2017}

Figura 41 - Frações retidas nas peneiras: (a) Cinzas pesadas; (b) Areia e (c) Char.

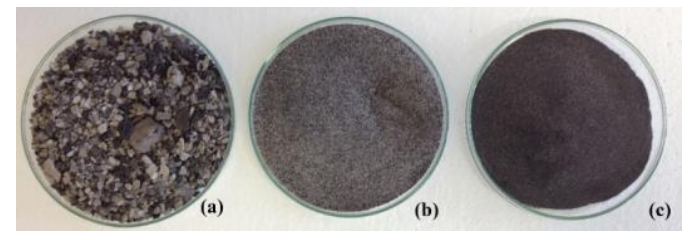

A Figura 5 expressa a distribuição granulométrica diferencial das cinzas pesadas no item (a) e o gráfico contido no item (b) refere-se à análise granulométrica acumulada. Observa-se no item (a) que a maior fração retida $(70 \%)$ refere-se ao diâmetro de $0,37 \mathrm{~mm}$. A análise do item (b) mostra que o diâmetro médio das partículas foi de $0,504 \mathrm{~mm}$, sendo a curva azul referente à fração retida acumulada e a curva vermelha referente à fração passante acumulada.

Figura 52 - Distribuição granulométrica diferencial (a); Análise granulométrica acumulada (b).
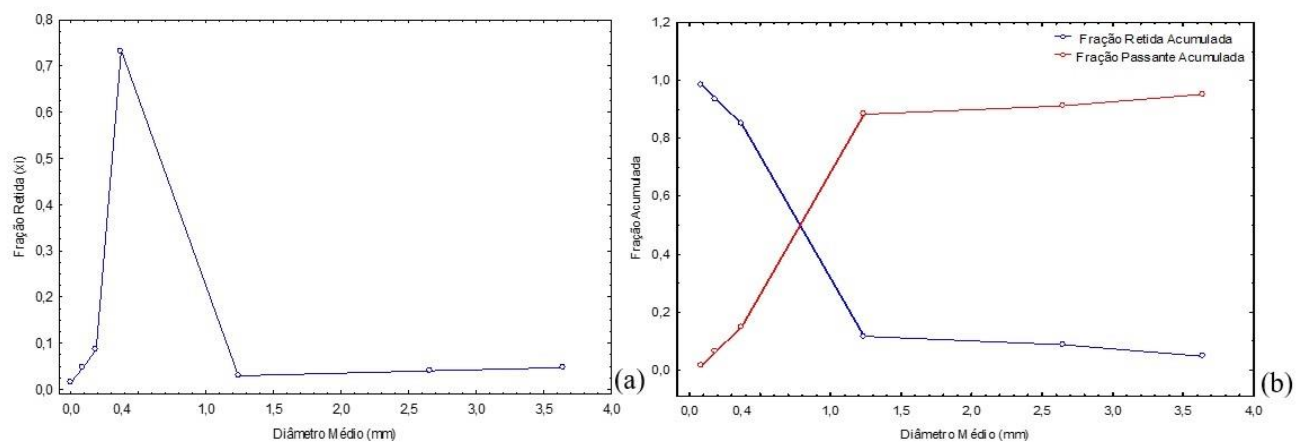

Sabedot et al. (2011), caracterizaram cinzas de diferentes usinas gaúchas (Braskem S/A, CMPC Celulose Riograndense e Tractebel Energia S/A), responsáveis pela queima do carvão mineral produzido e beneficiado na Copelmi Mineração Ltda. Obteve-se como resultado uma semelhança entre as curvas de distribuição granulométrica das cinzas das três usinas, sendo que mais de $55 \%$ das massas pesadas têm granulometria inferior a $0,6 \mathrm{~mm}$, sendo este valor próximo aos $0,504 \mathrm{~mm}$ encontrados para o diâmetro das cinzas pesadas.

\subsection{Colorimetria}

A análise colorimétrica não costuma ser usual para cinzas de carvão. Entretanto, como este trabalho tem por objetivos caracterizar as cinzas para viabilidade de futuras aplicações como matéria-prima para outros produtos ou mistura com outras substâncias, a cor pode ser um fator decisivo na sua aplicação. Com os resultados obtidos pelo colorímetro, estudaram-se as coordenadas $\mathrm{L}^{*}, \mathrm{a}^{*} \mathrm{e} \mathrm{b}^{*}$ dos sistemas SCI, que levam em consideração a iluminação do ambiente (Griebeler, 2013). A Tabela 1 possui os resultados obtidos a partir da análise colorimética das cinzas do carvão de gaseificação.

Tabela 1 - Análise colorimética das cinzas do carvão de gaseificação.

\begin{tabular}{|l|l|l|l|l|l|}
\hline & Valores Obtidos & Comparação & Braskem & CMPC & Tractebel \\
\hline
\end{tabular}




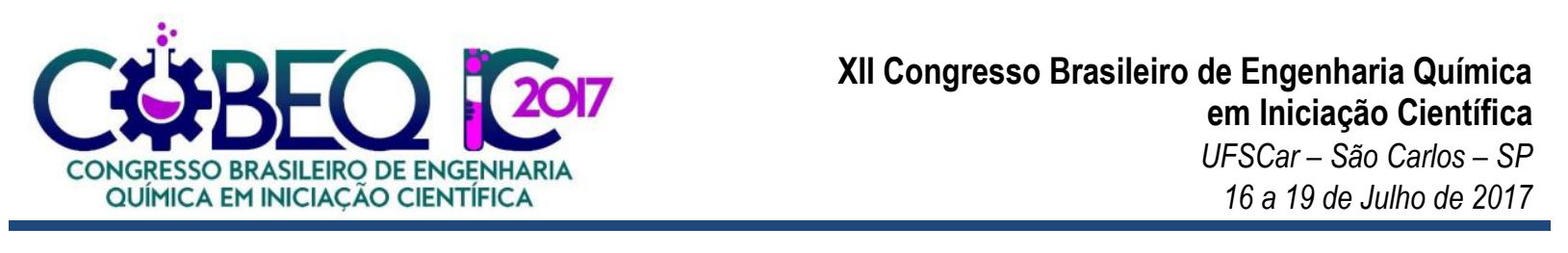

\begin{tabular}{|c|c|c|c|c|c|c|c|c|c|}
\hline & Leve & Pesada & Carvão Beneficiado & Leve & Pesada & Leve & Pesada & Leve & Pesada \\
\hline $\mathrm{L}^{*}$ & 10,34 & 47,99 & 23,17 & 74,58 & 31,78 & 72,63 & 31,72 & 62,15 & - \\
\hline$a^{*}$ & 1,87 & 1,97 & 1,26 & 0,12 & 0,59 & 0,10 & 0,79 & 0,11 & - \\
\hline $\mathrm{b}^{*}$ & 8,78 & 6,91 & 1,79 & 3,63 & 2,11 & 3,01 & 2,51 & 1,23 & - \\
\hline $\mathrm{C}$ & 8,97 & 7,18 & 2,19 & - & - & - & - & - & - \\
\hline$\Delta \mathrm{E}^{*}$ & 14,62 & 25,35 & - & - & - & - & - & - & - \\
\hline
\end{tabular}
do eixo azul/amarelo e $\mathrm{C}$ demonstra a saturação e $\Delta \mathrm{E}^{*}$ a variação da cor.

Os dados obtidos foram comparados com resultados estudados por Sabedot et al., (2011). Para a claridade, da cinza leve, os valores estão muito baixos se comparados com as cinzas das termelétricas, porém, proxímo do carvão beneficiado. Entretanto, o valor obtido para a cinza pesada está próximo aos da Braskem e CMPC (Celulose Riograndense). Para o parâmetro a* os valores, tanto para cinzas leves como pesadas, estão aproximados do carvão e maiores com relação às cinzas de combustão. Para $b^{*}$ os valores são maiores, tanto se comparados com o carvão, quanto para as outras cinzas. De acordo com o espaço cor é possível avaliar a saturação da cor, que aumenta ao afastar-se do centro através do incremento dos valores de $a^{*}$ e b*. Os valores de saturação, calculados, comprovam a cor característica das cinzas como próximas de cinza. A cinza leve possui valor maior se comparada com a pesada. Conforme pode ser observado pela Figura 2, a cinza leve (b) possui coloração mais próxima do preto e a pesada (a) aproximada de cinza. A análise de cor é importante, também para avaliar o nível de reflectância das cinzas, com eventual presença de material incobusto ou presença de substâncias químicas, como a sílica que iterferem diretamente na cor.

\section{3. Área Superficial (BET), Volume de Poro (BJH) e Raio Médio de Poro}

O raio médio dos poros obtidos para cinza leve é de 38,13 Ä, o volume total de poros (VP) de $0,05411 \mathrm{~cm}^{3} / \mathrm{g}$, o diâmetro médio de poro foi de $7,626 \mathrm{~nm}(76,26 \ddot{A})$, sendo classificado como mesoporo pela IUPAC. A área superficial encontrada foi de $28,0679 \mathrm{~m} / \mathrm{g}$, com valor de coefiente de correlação de 0,999551 relativo à análise. A área superficial (AS) está inversamente relacionada com o diâmetro ou tamanho médio de poros, de maneira que quanto maior a área superficial, menor o diâmetro do poro (Zen, 2016). O A Tabela 2 representa a comparação dos resultados obtidos com valores referenciados.

Tabela 2 - Área Superficial e Volume de Poros encontrados na análise.

\begin{tabular}{|c|c|c|}
\hline Cinzas & Leve Obtida & Zen (2016) \\
\hline $\mathrm{AS}\left(\mathrm{m}^{2} / \mathrm{g}\right)$ & 28,07 & $0,8 \pm 0,2$ \\
\hline $\mathrm{VP}\left(\mathrm{cm}^{3} / \mathrm{g}\right)$ & 0,05411 & $<0,01$ \\
\hline
\end{tabular}

As cinzas estudadas por Zen (2016) eram cinzas leves provenientes da combustão de carvão da mina de Candiota (RS) em leito pulverizado a $1400{ }^{\circ} \mathrm{C}$. Observa-se que a área superficial das cinzas leves da gaseificação é maior quando comparada com as cinzas do mesmo tipo de carvão, porém proveniente da combustão, como foi observado por Yoshiie et al., (2013), que estudou o comportamento de contaminantes presentes nas cinzas leves. Os autores coletaram partículas na saída de um reator de gaseificação de carvão, observando a 
adsorção de chumbo pelas cinzas. Com este resultado concluíram que grande parte do chumbo $(\mathrm{Pb})$ permanece adsorvido nas partículas de cinza.

\section{CONCLUSÃO}

A partir das análises realizadas observou-se que o processo de gaseificação, além de ser mais eficiente que a combustão para o tipo de carvão gaúcho, é uma alternativa de mitigação de impactos ambientais com grande potencial de emprego na região em que se localiza a mina de Candiota. Ademais, com a realização de todas as análises feitas neste trabalho e com os resultados observou-se que as cinzas possuem características físicas para serem aproveitadas como matéria-prima para desenvolvimento de outros produtos, bem como material adsorvente, material cerâmico, síntese de zeólitas, catalizadores e aditivos para indústria cimenteira.

\section{REFERÊNCIAS}

CREMASCO, M.A. (2012). Operações Unitárias em Sistemas Particulados e Fluidos Mecânicos. Ed. Blucher, São Paulo.

GRIEBELER, C.G. Colorimetria da madeira de Eucalyptus grandis W . Hill ex Maiden modificada termicamente e Eucalyptus grandis W . Hill ex Mai. 2013.

MELO, J.H.S. Simulação da gaseificação do carvão mineral de Candiota. 75 p. Bagé: Universidade Federal do Pampa, 2013.

NASCIMENTO, F.S. Desenvolvimento de protótipo de gaseificador de resíduos combustíveis em leito horizontal. 103 p. São Carlos: Universidade de São Paulo, 2014.

NUNES, K.G.P. Determinação dos parâmetros cinéticos da reação de oxicombustão de carvão mineral. 93 p. Porto Alegre: Universidade Federal do Rio Grande do Sul, 2012.

PELLEGRINO, R. Gaseificação de Carvão Mineral com Adição de Vapor e Remoção de H2S, em Leito Fluidizado. 146 p. Campinas: Universidade Estadual de Campinas, 2006.

PIRES, M.; QUEROL, X. Characterization of Candiota (South Brazil) coal and combustion byproduct. International Journal of Coal Geology, v. 60, p. 57- 72, 2004.

YOSHIIE, R. TAYAA, Y.; ICHIYANAGIA, T.; UEKIB, Y.; NARUSEA, I. Emissions of particles and trace elements from coal gasification. Fuel, v. 108, p. 67-72, 2013.

SABEDOT, S. BOER, S.C.; SUDSTRON, M.G. Caracterização e aproveitamento de cinzas da combustão de carvão mineral geradas em usinas termelétricas. 15 p. III Congresso Brasileiro de Carvão Mineral. Gramado, 2011.

Zen, B. P.; Feris, L. A.; Marcilio, N. R. (2016). Síntese de zeólitas a partir de cinzas de carvão e aplicação como adsorventes. Universidade Federal do Rio Grande do Sul. 